\title{
Development and identification of rheological model adapted for Powder Injection Moulding
}

\author{
CLAUDEL Dimitri, SAHLI Mohamed, BARRIERE Thierry and GELIN Jean-Claude \\ FEMTO-ST Institute / Applied Mechanics Department, 24 rue de l'Epitaphe, 25000 Besançon, France
}

\begin{abstract}
An Inconel based feedstock for manufacturing super alloy components by powder injection moulding is introduced. The relationship between the rheological properties and different parameters of the feedstock is investigated, based on a prescribed model. The method to determine the parameters of the rheological model for powder injection moulding is presented, including the important thermal effect.
\end{abstract}

\section{Introduction}

The Inconel based super alloys represents the important value in aeronautic and other industries. Powder injection moulding (PIM) is one of the most advantageous techniques for manufacturing super alloy components. The preparation of feedstock of Inconel based super alloys for injection moulding is the most crucial stage.

Researches on PIM process have had important developments in the last 20 years $[1,2,3]$. The feedstock plays a primary and decisive role on dimensions and mechanical properties of the PIM products. It dominates the process parameters for different stages of the PIM process, including injection moulding, debinding and sintering.

Numerical simulation of injection moulding is a very important way for designing the process and products. Accurate rheological model of the feedstock is crucial for correct simulations. The feedstock is injected with large shear rates up to $10^{5} \mathrm{~s}^{-1}$, and the melting temperature without degradation of the polymer binder.

The research on rheological model for PIM feedstock had been affected in the research team. Hidalgo Garcia proposed the suitable model, with the proofs of its application [4]. The model is shown in equation (1).

$$
\eta=\frac{C_{u}}{d_{50}} \cdot \exp \left(\frac{E_{a}}{R \cdot T}\right) \cdot\left(\frac{\phi_{\text {crit }}}{\phi_{\text {crit }}-\phi}\right)^{m} \cdot \eta_{\text {binder }}
$$

Where $\eta$ is viscosity, $E_{a}$ is the Arrhenius activation energy $\left(\mathrm{kJ} \cdot \mathrm{mol}^{-1}\right)$, R represents perfect gas constant $\left(\mathrm{J} \mathrm{K}^{-1}\right.$ $\left.\mathrm{mol}^{-1}\right), T$ is the temperature (K), $C_{u}$ is the ratio $d_{60} / d_{10}$, $\mathrm{d}_{10}, \mathrm{~d}_{50}$ and $\mathrm{d}_{60}$ are the particle sizes respectively at $10 \%$, $50 \%$ and $60 \%$, $\eta_{\text {binder }}$ is the viscosity of the binder formulation, $\phi_{\text {crit }}$ is critical load rate and $\phi$ is load rate.

\section{Materials and methods}

\subsection{Description of powders, binders and formulations}

This powder is a nickel-chromium-based superalloy, typically used in high-temperature and high-performance applications, particularly in the aeronautic industry. However, this nickel alloy is rather expensive; it is why it is very important to reduce the amount of wasted material [5]. In this context, the powder injection moulding is suitable.
A multi-component binders system was used to elaborate the feedstock. The binder composition is given table 1 and the relative volumetric fractions of powder are about $70 \%$. The surfactant acts as lubricant that enhances the dispersion of powder in the binder during mixing and also enhances the powder loading and green strength without sacrificing the flow properties of the mixtures

Table 1. Binder composition.

\begin{tabular}{|c|c|}
\hline Component & $\begin{array}{c}\text { Volumetric } \\
\text { fraction }\end{array}$ \\
\hline Polypropylene (PP) & 40 \\
\hline Polyethylene glycol (PEG) & 55 \\
\hline Stearic acid (SA) & 5 \\
\hline
\end{tabular}

Fig. 1 shows scanning electron microscopy (SEM) photography of Inconel powder without binder. The shape of powder particles is quasi-spherical. This shape is ideal for powder injection moulding.

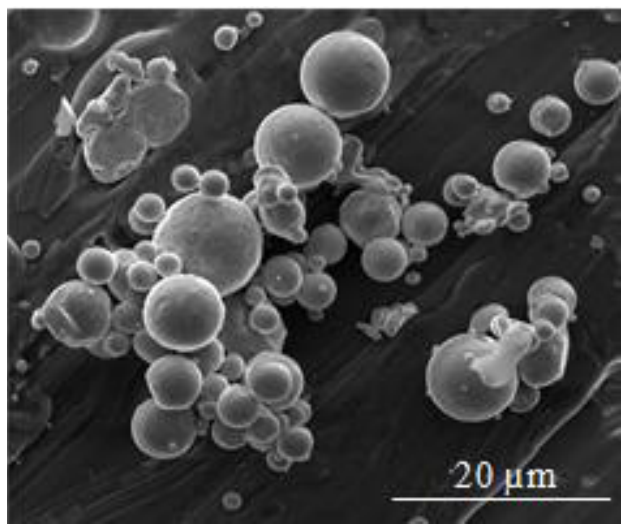

Figure 1. SEM analysis of Inconel powders.

\subsection{Processing methods}

\subsubsection{Description of mixing test}

Experiments related to the mixing of binders and feedstocks were carried out using a twin-screw




Brabender ${ }^{\circledR}$ Plastograph EC mixer with a pair of roller blades. The maximum capacity of the mixing chamber was $55 \mathrm{~cm}^{3}$. The mixer was connected with software to measure the mixing torque. The same processing conditions were used for each mixture, including a mixing temperature of $175^{\circ} \mathrm{C}$, a mixing time equal to 30 min and a mixing rotation speed of $30 \mathrm{rpm}$.

The powders were loaded when the temperature had stabilised at the required mixing temperature to facilitate homogeneous mixing of the powder and binder components. During a mixing test, the mixture homogeneity can be evaluated through the mixing torque curves. Uniform mixing is achieved when the torque reaches a stable, steady state value. After mixing, the feedstock was granulated in pellet form in order to be used during rheological characterization and to be fed easily in the injection process.

Figure 2 shows SEM photography of Inconel feedstock. The binder includes powder particles.

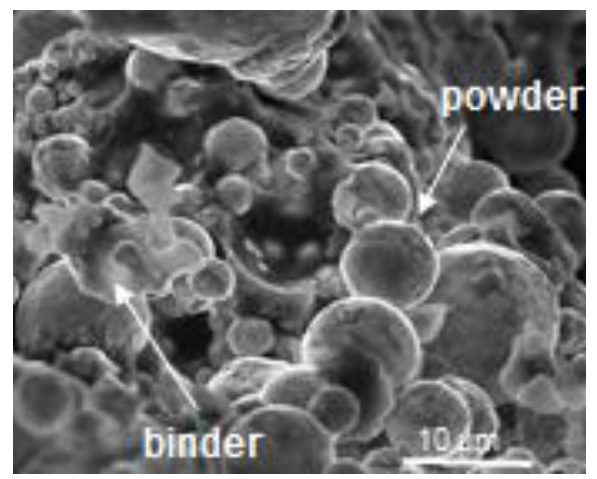

Figure 2. SEM photography of the Inconel feedstock

\subsubsection{Thermal characterisation}

The thermal characterization of each component of the binder and mixed feedstock is made by differential scanning calorimeter (DSC) and thermogravimetric analysis (TGA). The temperatures of glass transition, melting and degradation of each components of the binder were determined by DSC.

The tests were performed from room temperature to $500^{\circ} \mathrm{C}$ with heating and cooling rates $10^{\circ} \mathrm{C} / \mathrm{min}$.

Then, TGA was conducted for identical objects under inert atmospheric conditions. The samples were heated over a range of temperature from $25^{\circ} \mathrm{C}$ to $500^{\circ} \mathrm{C}$ with three different heating rates 2,5 and $10^{\circ} \mathrm{C} / \mathrm{min}$. These TGA scans allow inspection of the homogeneity for the feedstock after mixing.

\subsubsection{Rheology and particle size characterization}

The rheological properties of the resulting binder formulations and feedstocks were characterized using a capillary rheometer. First, all the binder granules were filled into rheometer barrel heated to 170,180 or $190^{\circ} \mathrm{C}$, beyond the melting temperature of the polymer and a slight pressure was applied using a piston and allowed for 5-10 min to attain equilibrium temperature throughout the materials. Then the binders were extruded through several tungsten carbide dies with $0.5,1$ and $2 \mathrm{~mm}$ diameters and measuring respectively 8,16 and $32 \mathrm{~mm}$ in length. The viscosity of binder was measured over a shear rate varying from $10^{3}$ to $10^{5} \mathrm{~s}^{-1}$, using the dies from 0,5 to $2 \mathrm{~mm}$ corresponding to 16 to $32 \mathrm{~mm}$ giving a ratio (L/D) equal to 16 .

To get viscosity curves with the largest possible shear rate range, a Mars rotational rheometer is employs. This kind of rheometer is suitable for low shear rate measures, opposite of the capillary rheometer. Thus, shear rates varying from 1 to $10^{3} \mathrm{~s}^{-1}$ were applied.

The particle size distribution was measured with a laser scattering particle analyser and the specific area was determined using ASAP2020 accelerated surface area and porosimetry system.

\section{Results and discussions}

Figure 3 illustrates the particle size distribution for an Inconel super alloy powder. The particle size distribution is shown in terms of the number of particles. As the graph shows, the $\mathrm{d} 10, \mathrm{~d} 50$ and $\mathrm{d} 90$ diameters that equivalent at $3,53 \mu \mathrm{m}, 6,24 \mu \mathrm{m}$ and $10,97 \mu \mathrm{m}$, respectively. The standard deviation in this case, was $0,86 \mu \mathrm{m}$. The measure of SSA indicates a specific area of $0,095 \mathrm{~m}^{2} / \mathrm{g}$.

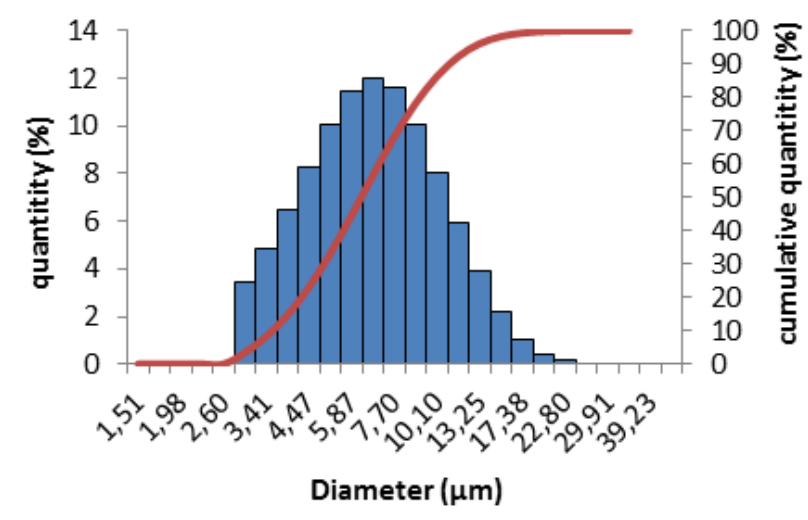

Figure 3. Particle size distribution for Inconel super alloy powders

\subsection{Viscosity of binder}

First, the viscosities of each component in the binder were measured separately by a rotational rheometer. The tests were realised for shear rates from $10^{-1}$ to $10^{3} / \mathrm{sec}$ at a temperature of $180^{\circ} \mathrm{C}$. Then, identification of the parameters for Carreau-Yasuda model, adapted for pure polymer [7], was realized (see equation. 2). The identified models, compared to the experimental values, are shown in Figures 4 and 5.

$$
\eta=\eta_{0}\left(1+(\lambda \dot{\gamma})^{a}\right)^{(n-1) / a}
$$

$\eta_{0}$ shear apparent viscosity at zero shear rate (Pa.s), $\lambda$ is (Cross) time constant, $\dot{\gamma}$ is shear rate (/s), a is a constant. 

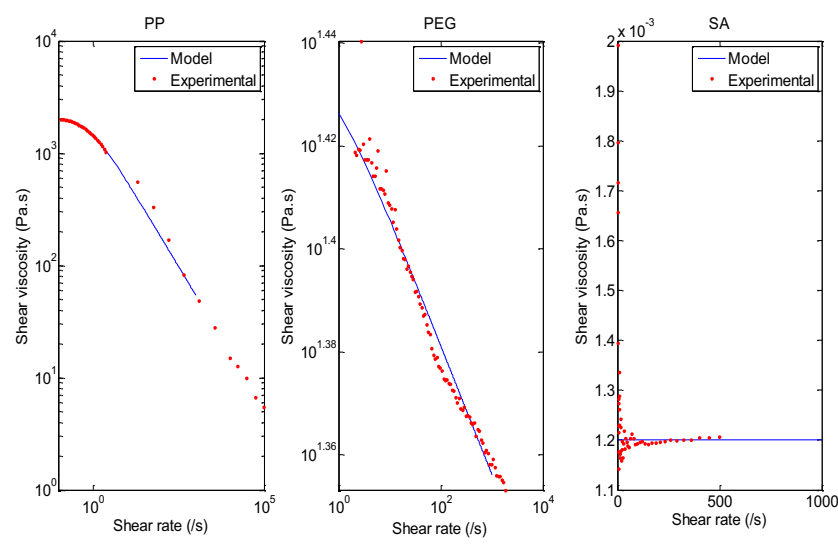

Figure 4. Identifications of Carreau-Yasuda law PP, PEG and SA

Then, three binders were elaborated with the components of different quantities. The binder compositions are represented in Table 2.

Table 2. Binder composition.

\begin{tabular}{|c|c|c|c|}
\hline & PP & PEG & SA \\
\hline Mixture 1 & 40 & 40 & 20 \\
\hline Mixture 2 & 60 & 15 & 25 \\
\hline Mixture 3 & 70 & 20 & 10 \\
\hline
\end{tabular}
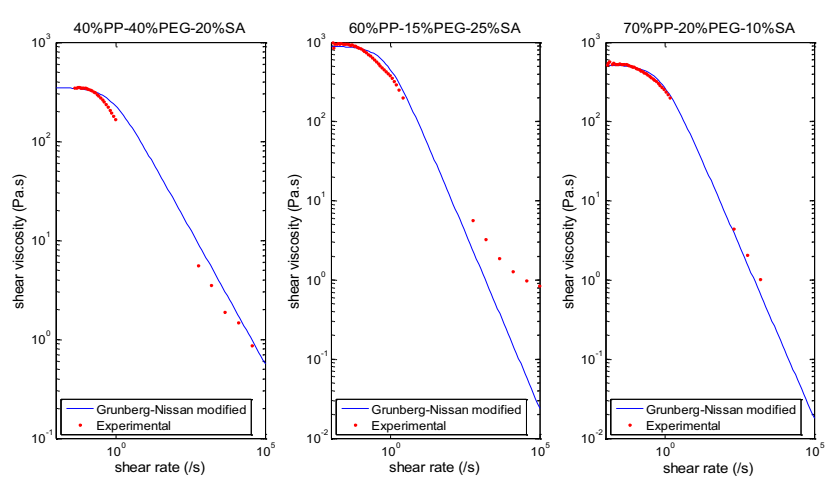

Figure 5. Identified Grunberg-Nissan models for 3 different binders.

The viscosities of different binders were measured. The Grunberg-Nissan modified law was identified for each of the binder. This law was used by Kukla [8], expressed by Eq. 3. The identified models for each binder are shown in Fig. 4.

$$
\begin{gathered}
\log (\eta)=x_{1} \cdot \log \left(\eta_{1}\right)+x_{2} \cdot \log \left(\eta_{2}\right)+x_{3} \cdot \log \left(\eta_{3}\right)+ \\
x_{1} x_{2} d_{12}+x_{1} x_{3} d_{13}+x_{2} x_{3} d_{23}+x_{1} x_{2} x_{3} d_{123}
\end{gathered}
$$

Where $\eta$ is the viscosity of binder, $\eta_{1,2,3}$ are viscosities of components, $\mathrm{x}_{1,2,3}$ are mole fractions of components and $\mathrm{d}_{12,13,23,123}$ are curve fitted parameters.

These identifications allowed obtaining significant correlations among experimental and numerical behaviours for binders with different proportions. So, the Grunberg-Nissan modified law is suitable modelling viscosities of binder system.

\subsection{Influence of the powder loading rate on the viscosity}

To observe the influence of powder loading rate on viscosity, three feedstocks with different powder loading rates respectively of 68,70 and $72 \%$ were use. Feedstock viscosities are measured using capillary rheometer with a $1 \mathrm{~mm}$ diameter die and shear rate including between 100 and $10000 / \mathrm{s}$.

The shear viscosity of feedstock versus the power loading and shear rate is shown in Figure 6. The viscosity increases more significantly when the powder loading becomes more than $70 \%$. At $72 \%$, the powder charge approaches to the maximal value [6].

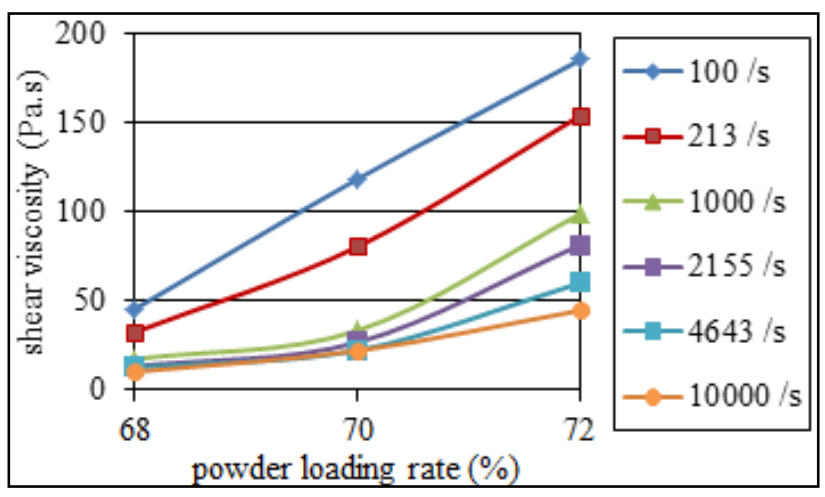

Figure 6. Evolution of shear viscosity of feedstock versus powder loading rate and shear rate for Inconel feedstock

\subsection{Apparent viscosity and identification of the rheological parameters}

The results of the viscosity measurements of the Inconel elaborated feedstocks are shown in fig. 6. It exhibited pseudo-plastic flow behaviour and the viscosity decreased as the shear rate increased at all working temperatures. This viscosity is plotted for 170, 180 and $190^{\circ} \mathrm{C}$. Shear viscosity decreases with shear rate. This behaviour matches with pseudo-elastic behaviour.



Figure 7. Comparison of rheological constitutive modeling after parameter identification of shear viscosity for Inconel feedstock 
The first identification was carried out with the power-law model. This identification allows defining the flow behaviour index equivalent to a value of 0.36 . For this model, only the experimental measuring with shear rate higher as $10^{3} \mathrm{~s}^{-1}$ were considerate.

The second identification was perform with the generalized constitutive law model and is given on the figure 7 . With this model, the experimental measuring and analytical modeling are almost. The parameters allowing this proper correlation between analytical and experimental curves are given in the table 3 .

Table 3. Identified parameters.

\begin{tabular}{|c|c|c|c|}
\hline $\mathbf{T}\left({ }^{\circ} \mathbf{C}\right)$ & $\mathbf{a}$ & $\boldsymbol{\lambda}$ & $\boldsymbol{\eta}_{\mathbf{0}}$ (Pa.s) \\
\hline 170 & 0.6148 & 0.0119 & 207.5 \\
\hline 180 & 0.7344 & 0.01755 & 158.9 \\
\hline 190 & 0.8591 & 0.00995 & 64.47 \\
\hline $\mathbf{n}$ & $\mathbf{E a ~ ( k J / m o l ) ~}$ & $\mathbf{m}$ & $\mathbf{R}^{\mathbf{2}}$ \\
\hline 0.36 & 20 & 0.009 & 0.998 \\
\hline 0.36 & 20 & 0.009 & 0.984 \\
\hline 0.36 & 20 & 0.009 & 0.988 \\
\hline
\end{tabular}

\section{Conclusions}

The determination of rheological parameters using data obtained through standard viscosimetrics flows opens the possibility of building reliable analytical models, which can be used in the injection simulations. The present work aims at the identification of rheological parameters associated to a nonlinear constitutive equation. Firstly, a robust analysis has been used, in order to determine the constitutive coefficient values, starting from experimental data obtained by rheological tests. Then, an extensive sensitivity analysis has been performed.

The aim of this work is to examine a proper constitutive model to describe more accurately the influence of the shear rates and temperature on the feedstock behaviour in large shear rates ranges.

To improve the rheological sensitivity on the injection simulations, in a future work, we propose to analyze the influence of a more complex law. It is then necessary to take into account the solids loading, binder ingredient and particle size of powders and then interaction between powders and binders.

\section{References}

1. Ö. Özgün, H. Özkan Gülsoy, R. Yilmaz, and F. Findik, J. Alloy Compd. 546 (2013) 192-207.

2. C. Quinard, J. Song, T. Barriere, and J. C. Gelin, Powder Technol. 208 ( 2011) 383-389.

3. T. Shivashankar, S. Ravi, K. Enneti, S-J. Park, R.M. German and S.V. Atre, Powder Technol. 243 (2013) $79-84$.

4. J. Hidalgo, A. Jiménez-Morales, T. Barriere, J.C. Gelin, J.M. Torralba, Leganés, November 2013, 111113.
5. J. Lambarri, J. Leunda, V. García Navas, C. Soriano and C. Sanz, Opt Laser Eng. 51 (2013) 813-821.

6. X. Kong T. Barriere and J. C. Gelin, J. Mater Process Tech. 212 (2012) 2173-2182.

7. K.Y. Yasuda, R.C Armstrong and R.E. Cohen, Rheol. Acta.20 (1981) 163-178.

8. C. Kukla, I. Duretek and C. Holzer, EPMA. (2013) 305-310. 